\title{
Photoluminescence characteristics of strontium titanate thin films prepared by spray pyrolysis
}

\author{
S. Aisah Mat*, K. Deraman, R. Hussin, W. Nurulhuda W. Shamsuri, B.Ismail, S. Maarof \\ Department of Physics, Faculty of Science, UTM, 81310 UTM Skudai, Johor, Malaysia \\ *Corresponding Author: sitiaisah_mat@ymail.com (S. Aisah Mat)
}

\section{Article history :}

Received 10 January 2014

Revised 2 April 2014

Accepted 25 May 2014

Available online 6 June 2014

GRAPHICAL ABSTRACT

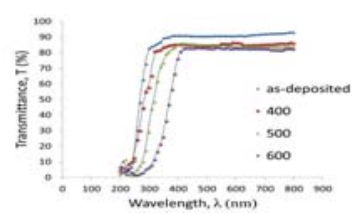

\section{ABSTRACT}

Strontium titanate, $\mathrm{SrTiO}_{3}$ thin films were successfully prepared by spray pyrolysis. The strontium titanate, STO precursor solid thin film were fabricated from an aqueous solution of $\mathrm{Sr}\left(\mathrm{NO}_{3}\right)_{2} /\left[\left(\mathrm{CH}_{3}\right)_{2} \mathrm{CHO}\right] 4 \mathrm{Ti} / \mathrm{HNO}_{3}=19: 1: 20$ (molar ratio) at room temperature on a substrate. The asdeposited STO thin film with those annealed at different temperature were prepared. Photoluminescence spectra of thin films were obtained using Photoluminescence Spectrophotometer and optical properties were carried out by using Shimadzu Uv-Vis Spectrophotometer. In conclusion, the band gap energy and the bandwidth of thin films have been analysed.

Keywords: Transparent, Photoluminescence, Spray pyrolysis, Thin films, $\mathrm{SrTiO}_{3}$

(C) 2014 Penerbit UTM Press. All rights reserved http://dx.doi.org/10.11113/mjfas.v10n2.261

\section{INTRODUCTION}

There is much study in the fields of science and technology in perovskite-type structured compounds with the chemical $\mathrm{ABO}_{3}$ formula (A and $\mathrm{B}$ are cations while $\mathrm{O}$ is the oxygen anion), owing to their wide range of electronic applications [1-2]. Within this class of compounds, $\mathrm{SrTiO}_{3}$, in the crystalline form, display semiconductor behaviour. In additional, when pure $\mathrm{SrTiO}_{3}$ samples are excited by radiation above their energy band gaps, which normally range from $3.2 \mathrm{eV}$ to $3.4 \mathrm{eV}$, a broad luminescent band appears at low temperatures [3-4].

In general, $\mathrm{SrTiO}_{3}$ films are amorphous when growing at low temperatures and polycrystalline when growing at high temperatures. For their applications in electrical devices, there exists a dilemma that polycrystalline films tend to exhibit both high dielectric constants and high electrical conductivity, while amorphous films tend to exhibit both low dielectric constants and low electrical conductivity [5-6]. Thus, there is a compromise when choosing the growing temperatures. When considering luminescent properties, correspondingly, one also might have to meet the similar problem of choosing a proper temperature to obtain the desired photoluminescent characteristics [6]. Therefore, the study of the luminescent properties of $\mathrm{SrTiO}_{3}$ thin films deposited at various annealing temperatures should be of interest for providing some useful references for their potential applications in integrated optics devices.

\section{EXPERIMENTAL}

\subsection{Materials, method and instruments}

$\mathrm{SrTiO}_{3}$ thin films were processes by the polymeric precursor method. A flow chart of the $\mathrm{SrTiO}_{3}$ synthesis used in this study is outlined in Fig. 1.

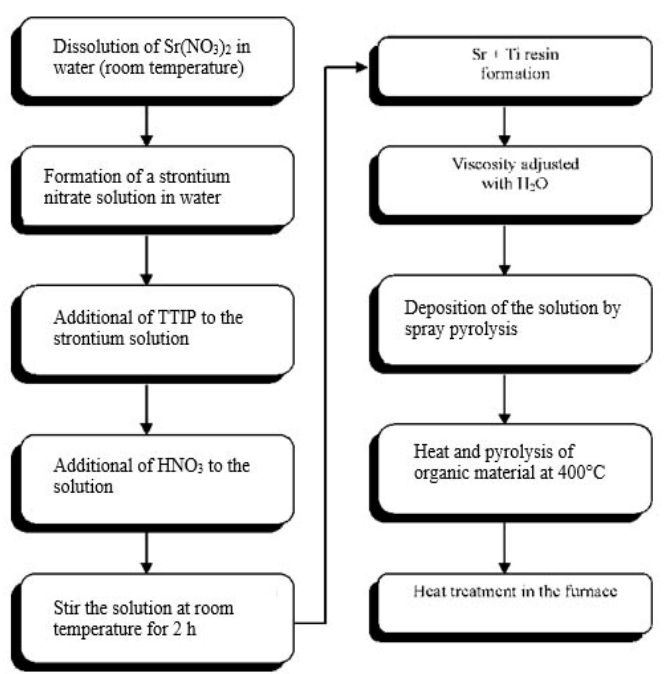

Fig. 1 Flow chart illustrating the procedure for the preparation of $\mathrm{SrTiO}_{3}$ thin films production.

The starting precursor solution were prepared by dissolution strontium nitrate $\left[\mathrm{Sr}\left(\mathrm{NO}_{3}\right)_{2}\right.$; purity, $\left.98 \%\right]$ in 
ultrapure water. After complete dissolution of the $\mathrm{Sr}\left(\mathrm{NO}_{3}\right)_{2} \quad$ salt, titanium tetraisopropoxide $\left(\left[\left(\mathrm{CH}_{3}\right)_{2} \mathrm{CHO}\right] 4 \mathrm{Ti} ;\right.$ TTIP, 97\%) was slowly added and after homogenation of the Ti solution, nitric acid, $\mathrm{HNO}_{3}$ was added to promote polymerization of the mixed nitrates by polyesterification reaction. The polymeric precursor solution was stirred for 2 hour at room temperature before nebulization. The molar ratio between the strontium and titanium cations was 19:1, and the nitric acid ratio at 20.

Corning silicon glass ( $\left(\begin{array}{lll}1 & 0 & 0\end{array}\right)$ was used as a substrate. This substrate was heated at $400{ }^{\circ} \mathrm{C}$ on the hot plate for $1 \mathrm{~h}$ to stabilize the substrate temperature. Then, this substrate was spray using atomizer by dropping a small amount of the polymeric precursor solution onto it. Flow rate of the oxygen carrier gas and spray time were fixed at $4.0 \mathrm{~L} / \mathrm{min}$ and $15 \mathrm{~min}$, respectively. The heat treatment was carried out in tube furnace in an open air at a heating rate $5^{\circ} \mathrm{C} / \mathrm{min}$ to pyrolyze the organic materials, followed soon thereafter by heating at different temperatures for $2 \mathrm{~h}$ to crystallize them.

\subsection{Characterization}

The $\mathrm{SrTiO}_{3}$ films were structurally characterized by $\mathrm{X}$-ray diffraction (XRD) ( $\mathrm{Cu} \mathrm{K} \alpha$ radiation). The diffraction patterns were recorded on a Siemens D5000 machine in a $\theta-2 \theta$ configuration, using a graphite monochromator. Uv -Vis diffuse reflectance spectrum of samples were measured by using an UV - Vis spectrometer (Shimadzu $3101 \mathrm{PC})$ at room temperature in the wavelength range of $200-800 \mathrm{~nm}$. The photoluminescence spectra were obtained using a xenon short arc lamp luminescent spectrophotometer (Perkin Elmer, LS 55) monitored at ambient temperature. The excitation wavelength used for PL characterization was fixed at $250 \mathrm{~nm}$ while the slit width used was $300 \mathrm{~nm}$. All the measurement was taken at room temperature.

\section{RESULTS \& DISCUSSION}

\subsection{XRD}

Fig. 2 shows the XRD patterns of the $\mathrm{SrTiO}_{3}$ thin film annealed at different temperatures for $2 \mathrm{~h}$ in an open air. The as-deposited $\mathrm{SrTiO}_{3}$ thin films shows that no peak appear in XRD patterns was amorphous and crystallized into perovskite $\mathrm{SrTiO}_{3}$ after annealing at $600^{\circ} \mathrm{C}$ for $2 \mathrm{~h}$ in air. Increasing temperature resulted in an increase in the crystallinity. The crystal lattice constant calculated using XRD data is $3.865 \AA$, which is smaller than the theoretical value for $\mathrm{SrTiO}_{3}$ single crystal (3.905 $\AA$ ).

A diffuse XRD pattern is observed at $400^{\circ} \mathrm{C}$, indicating the formation of an inorganic amorphous precursor after the pyrolysis process. For temperature $500^{\circ} \mathrm{C}$, begins the crystallization of the $\mathrm{SrTiO}_{3}$ perovskite phase. No intermediate phase was observed which suggests a direct crystallization from the amorphous phase. However, crystallization structure patterns were identified in the film anneal at $600^{\circ} \mathrm{C}$. Similar XRD spectra of SrTiO3 crystalline thin films were obtained by Leite et, al. where the characterization of $\mathrm{Ba}_{1-x} \mathrm{Sr}_{\mathrm{x}} \mathrm{TiO}_{3}$ films showed that phase crystallizes at $600^{\circ} \mathrm{C}$ from an inorganic amorphous matrix and no intermediate crystalline phase was observed.

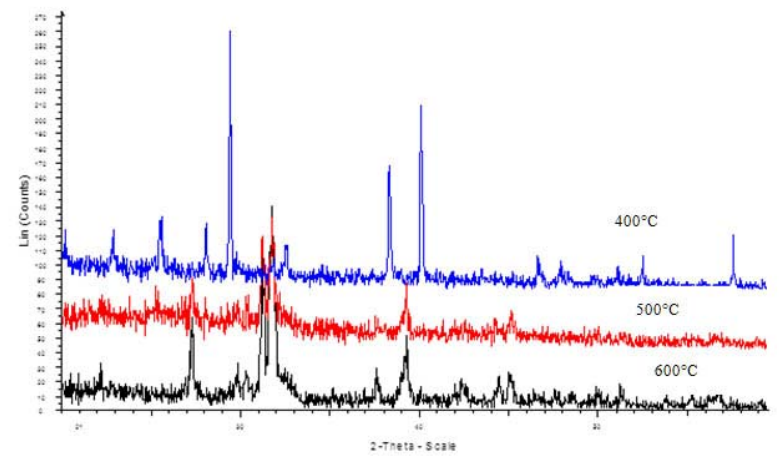

Fig. 2 The XRD patterns of the $\mathrm{SrTiO}_{3}$ thin films annealed at different temperature $\left(400^{\circ} \mathrm{C}, 500^{\circ} \mathrm{C}, 600^{\circ} \mathrm{C}\right)$

\subsection{Optical Properties}

The optical properties transmission spectra shown in Fig. 3 demonstrate that the film was highly transparent (transmittance $\geq 80 \%$ ) in the visible region for both the asdeposited thin film and those annealed at different temperature. The high transmittance indicates a fairly smooth surface and relatively good homogeneity of the film. The oscillations in the transmittance curve due to interference have low depths of modulation indicating inhomogeneity of the films across the light beam [7]. Overall, the films annealed at higher temperatures displayed lower transmittance.

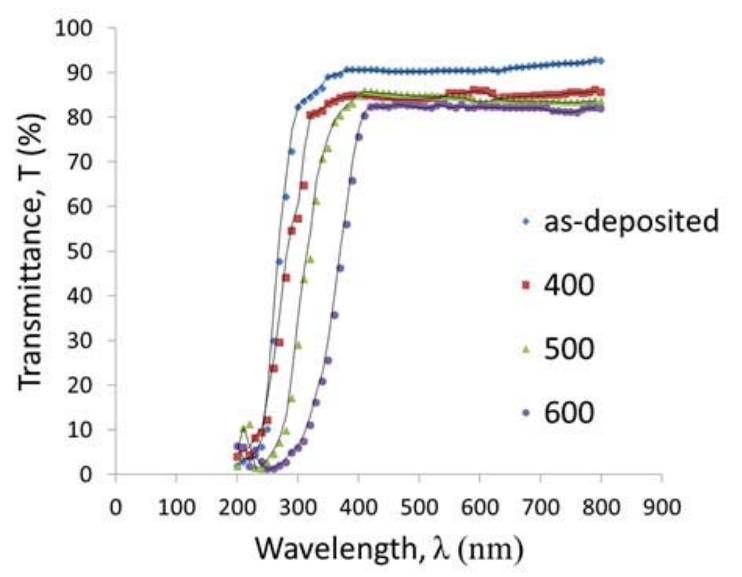

Fig. 3 Optical transmittance spectra of the as-deposited STO precursor solid thin film and those annealed at different temperatures $\left(400^{\circ} \mathrm{C}, 500^{\circ} \mathrm{C}, 600^{\circ} \mathrm{C}\right)$

All the films showed a sharp absorption onset in the near-UV region. The absorption edge of the films shifts to longer wavelengths as the annealing temperature increases. It is known that exciton-phonon coupling or dynamic 
disorder is the main factor contributing to absorption edge broadening for crystalline materials.

For the high-energy absorption region, the relation between transmittance $(T)$ and absorption coeffient $(\alpha)$ can be expressed as

$\alpha=1 / d \ln \left(T_{100} / T\right)$

where $\mathrm{T}$ is the normalized transmittance and $\mathrm{d}$ is the film thickness, neglecting the reflection coefficient, which is negligible and insignificant near the absorption edge [8].

The relation of absorption coefficient and incident photon energy hv can be written as

$(\alpha h v)=A_{1}\left(h v-E_{g}{ }^{1}\right)^{1 / 2}$

and

$(\alpha h v)=A_{2}\left(h v-E_{g}\right)^{2}$

for allowed direct transition and indirect transition, respectively, where $A_{1}$ and $A_{2}$ are constants, and $E_{g}{ }^{1}$ and $\mathrm{E}_{\mathrm{g}}{ }^{2}$ are the direct and indirect band gap energies related to direct transition and indirect transition, respectively [9].

A direct transition occurs when the valence band maximum and the conduction band minimum are at the same point in the Brillouin zone, and an indirect one occurs when the minimum and the maximum are at different places. For a direct transition, a photon with energy hv can be absorbed by promoting a valence band electron to the conduction band, creating an electron-hole pair. This process involves a two-body collision (electron and photon) accompanied by strong light absorption, whereas for an indirect transition between two bands with different wavevectors, both the kinetic energy and the potential energy of an electron must be changed, which requires the assistance of a phonon [10]. Hence, this process involves a three-body collision (electron, photon and phonon) and relatively weak light absorption.

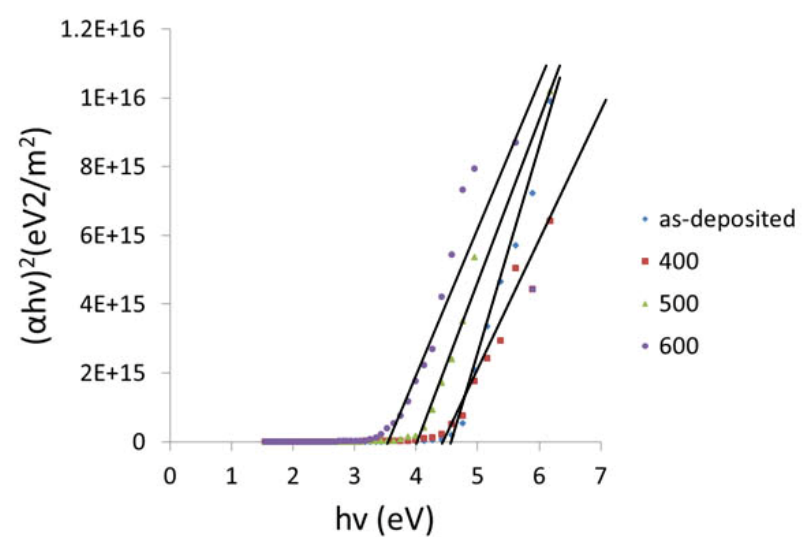

Fig. 4 Direct transition band gap energies of the as deposited STO precursor solid thin film and those annealed at different temperature $\left(400^{\circ} \mathrm{C}, 500^{\circ} \mathrm{C}, 600^{\circ} \mathrm{C}\right)$
The usual method of determining band gap energy is to plot a graph between $(\alpha h v)^{\mathrm{n}}(\mathrm{n}=2$ or $1 / 2$ for direct allowed transition and indirect transition) and photon energy hv, and to compare which value of $\mathrm{n}$ gives the best linear relation in the band edge region. The graph plotted $(\alpha h v) n$ against $h v$ for the as-deposited thin film and those annealed at different temperatures, and results the best fit was obtained for $\mathrm{n}=2$, indicating a direct allowed transition as shown in Fig. 4.

Annealing at high temperature, such as $600^{\circ} \mathrm{C}$ and $500^{\circ} \mathrm{C}$, the band gap energy was saturated to about $3.60 \mathrm{eV}$ and $4.00 \mathrm{eV}$, comparable to that for a sol-gel derived thin film with different thickness. However, it is higher than that for the single crystal $(3.37 \mathrm{eV}-3.41 \mathrm{eV})$, except that proposed by Benthem et al. 1 is $3.75 \mathrm{eV}$. Such a different may be due to poor crystallinity and the presence of oxygen vacancies. As the annealing temperature increases, larger grains are formed which brings increased band edge steepness. This may be explained by the reduction of the surface to volume ratio as crystals grow larger since the localized states most likely arise from surface states [8]. When the sample were heated at $400^{\circ} \mathrm{C}$ as shown in Fig. 4, no obvious change with as-deposited sample and the band gap energy was $4.4 \mathrm{eV}$, which was comparable to Bao et al.

\subsection{Photoluminescence}

The emission spectrums shown in Fig. 5 represent the rest of the as-deposited $\mathrm{SrTiO}_{3}$ thin film and those annealed at different temperature emission spectra. As the annealing temperature is high enough to complete the structural transformation, higher PL intensity and a spectral blue shift $(450-475 \mathrm{~nm})$ are observed, as shown in Fig. 5.

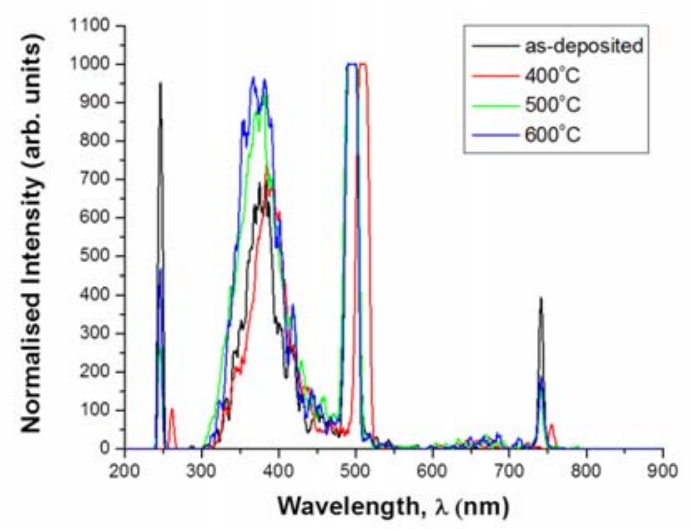

Fig. 5 A typical emission spectrum of the as-deposited STO precursor solid thin film and those annealed at different temperatures $\left(400^{\circ} \mathrm{C}, 500^{\circ} \mathrm{C}, 600^{\circ} \mathrm{C}\right)$ under excitation at $250 \mathrm{~nm}$.

The maximum intensity is located at $384 \mathrm{~nm}$, very close to that of $\alpha$-phase STO reported by C"olle et al. The previous publications [7], except for the case of reduced intensity reported by Papadimitrakopoulos et al., also 
revealed that an increased substrate temperature or annealing process for $\mathrm{SrTiO}_{3}$ film caused higher PL intensity. This is in agreement with these results.

The reason for the blue shift, similar to that reported previously, is deduced to be the more efficient Rayleigh scattering for shorter wavelengths on STO crystal grains [11]. The strong wavelength dependence of the scattering $\left(\sim \lambda^{-4}\right)$ means that blue light is scattered much more than red light, so the PL emission should be more effective at shorter wavelengths (the blue end of the spectrum) [12].

\section{CONCLUSION}

Polycrystalline $\mathrm{SrTiO}_{3}$ thin films were prepared by the polymeric precursor method on corning silicon glass substrate at different annealing temperature. XRD analysis showed an increasing temperature resulted in an increase in the crystallinity while the as-deposited showed no signal of XRD patterns. The as-deposited film and those annealed at $400^{\circ} \mathrm{C}$ and $500^{\circ} \mathrm{C}$ revealed band gap energies in the range $4.0-4.4 \mathrm{eV}$, while band gap energy for the crystallized film at $3.60 \mathrm{eV}$. The peak for the emission spectra was observed at $384 \mathrm{~nm}$ (violet emission) which shift to blue emission ( $\geq 450 \mathrm{~nm})$.

\section{ACKNOWLEDGEMENT}

The authors thank the Department of Physics, Faculty of Science and Universiti Teknologi Malaysia, Johor as well as to Malaysian Government (FRGS) vot 4F005 for funding the project.

\section{REFERENCES}

[1] M. Tokoda, Y. Hamaji, K. Tomoro, and D.A. Payne, Jpn. J. Appl. Phys. 32 (1993) 4158.

[2] V. Craciun, and R.K. Singh, Appl. Phys. Lett. 76 (2000) 1932.

[3] R.N. Schwartz, B.A. Wechsler, and L. West, Appl. Phys. Lett. 67 (1995) 1352.

[4] L.H. Parker, and B.A. Tasch, IEEE Circuits Devices Mag. 6 (1990) 17.

[5] Z. Wang, V. Kugler, U. Helmersson, N. Konofaos, E. K. Evangelou, S. Nakao, and P. Jin, Appl. Phys. Lett. 79 (2001) 1513.

[6] Z. Wang, V. Kugler, U. Helmersson, E. K. Evangelou, N. Konofaos, S. Kakao, and P. Jin, Philos. Mag. B 82 (2002) 891

[7] S. M. Zanetti, E. R. Leite, E. Longo and J. A. Varela, J. Mater. Res. 13 (1998) 2932.

[8] L. J. Meng and M. P. Dos Santos, Thin Solid Films. 226 (1993) 22

[9] P. Y. Yu and M. Cardona, Fundamentals of Semiconductors, p.343 (Springer,Berlin1996).

[10] G. A. Barbosa, R. S. Katiyar, and P. S. Porto, J. Opt. Soc. Am. 68 (1978) 610.

[11] C"olle M, Gmeiner J, Milius W, Hillebrecht H and W. Br"utting, Adv. Funct. Mater. 13 (2003) 108

[12] Papadimitrakopoulos F, Zhang X M and Higginson K. A, IEEE J. Sel. Top. Quantum Electron. 4 (1998) 47.

[13] K. V. Benthem, C. Elsasser, and R. H. French, J. Appl. Phys. 90 (2001) 64.

[14] D. Bao, X. Yao, N. Wakiya, K. Shinozaki, and N. Mitzutani, Appl. Phys. Lett. 79 (2001) 69. 